\title{
Evaluation of Skeletal Jaw Relation by Different Cephalometric Angles for Sample of Kurdish Young Adults in Sulaimani City-A Cephalometric Study
}

Shiler Abdul Hammed Mohammed

Ministry of Health

Trefa Mohammed Ali

University of Sulaimani College of Dentistry

Zhwan Jamal Rashid ( $\boldsymbol{D}$ zhwan.rasheed@univsul.edu.iq)

University of Sulaimani College of Dentistry https://orcid.org/0000-0003-2440-6833

\section{Research Article}

Keywords: Skeletal sagittal jaw relationship, W Angle, ANB angle, Beta angle, Wits appraisal

Posted Date: June 2nd, 2021

DOl: https://doi.org/10.21203/rs.3.rs-543835/v1

License: (c) (i) This work is licensed under a Creative Commons Attribution 4.0 International License.

Read Full License 


\section{Abstract}

\section{Background/Objectives}

An accurate evaluation of skeletal sagittal jaw relationship has an important role in orthodontic diagnosis and treatment planning. This study was done to establish cephalometric norms of all types of malocclusion using ANB, Wits appraisal and Beta angle, and evaluate the significance of W angle in comparison to these parameters.

\section{Subjects and Methods}

Ninety pre-treatment lateral cephalograms of male and female patients aged 18-28 years from Sulaimani City that met the sample criteria were traced digitally by the Easy Dent 4 software program. The sample was divided into three groups of skeletal malocclusion, class I, II, and III, based on ANB angle, Beta angle, and Wits appraisal, each group consisting of 30 patients. For each subject the following cephalometric parameters were measured: ANB angle, Beta angle, Wits apprasial, and W angle.

Statistical analysis

The Statistical Package for Social Sciences was used for analyzing data. ANOVA test was used to compare means of the three study groups. The post-hoc test was used to compare each two groups, Pearson correlation coefficient ( $r$ ) was used to assess the strength of correlation between two numerical variables, and coefficient of variability was used to measure the extent of variability of each variable in relation to the population. The $p$ value of $\leq 0.05$ was considered statistically significant.

\section{$\underline{\text { Results }}$}

Significant differences were found in the ANB angle, Beta angle, Wits appraisal and W-angle in all 90 patients. The coefficient of variability showed that Wits appraisal was the most variable parameter and $\mathrm{W}$ angle was the least variable parameter.

\section{Conclusions}

ANB angle, Beta angle, Wits appraisal and W-angle are significant parameters to assess the sagittal jaw relationship. The use of $\mathrm{W}$ angle, along with other parameters, can provide more accurate assessment of the sagittal skeletal jaw relationship as it has the least coefficient of variance; it should therefore enable better diagnosis and treatment planning for patients.

\section{Background}

In the field of orthodontics, discrepancies of the jaws can be described in three planes, namely transverse, sagittal and vertical (1). Of these, the sagittal discrepancies are of most concern to the patient. Hence, in orthodontic diagnosis and treatment planning, an accurate measurement of sagittal discrepancy is 
critical (2). However, the evaluation of the sagittal relationship of maxilla and mandible has posed a major problem. The causes of this problem are the change in the sagittal relationship due to rotations of the jaws during growth, and a lack of validity of the various methods proposed for their evaluation (3).

The importance of the sagittal jaw relationship for patients and orthodontists has led to introduction of many linear and angular cephalometric parameters for its measurement, including ANB angle, Wits appraisal, and Beta angle (4). But they all have shortcomings and drawbacks (5).

To overcome these problems, in 2013, Bhad et al. (6) introduced the W-angle. This is the angle between the perpendicular line from point $M$ to the $S-G$ line and the $M-G$ line (Fig. 1). The use of this angle has many advantages. Firstly, it has not dependent on unstable landmarks or dental occlusion. Therefore, it is a valuable tool for assessing true sagittal changes because of growth and orthodontic treatment (6). Secondly, in skeletal patterns with clockwise or counterclockwise rotation of the jaws as well as during transitional periods when vertical facial growth is taking place, $W$ angle is a useful sagittal parameter (7). Finally, it can be used for treatment planning during orthopedic or orthognathic procedures as this angle is independent of the cranial base length (position of point $\mathrm{N}$ ) that sometimes camouflages the true skeletal class I, II and III patterns (8).

Moreover, cephalometric analysis is practiced by comparing the patient's radiographic measurements with norms or standard values, most of which are obtained from samples of European or American populations. Therefore, the application of these norms in other populations may give error because of possible ethnic and racial variations (7).

The aim of this study is to evaluate the significance of $\mathrm{W}$ angle in the diagnosis of the antero-posterior jaw relationship in comparison to other skeletal sagittal dysplasia indicators, including ANB angle, Beta angle and Wits appraisal, in class I, class II, and class III types of malocclusion. And to establish cephalometric norms of all types of skeletal sagittal malocclusion using ANB, Wits appraisal, and Beta angle for a sample of Kurdish young adults in Sulaimani City.

\section{Subjects And Methods}

The sample consisted of 124 cephalograms of the total 311 patients examined clinically (male and female) with class I, class II, or class III malocclusion. Ninety patients fitted the criteria of the study, while 34 cases were excluded due to poor quality of cephalometric radiograph or failure to communicate with the patients. Among the selected cases $40 \%$ were male (36 cases) and $60 \%$ were female (54 cases). These 90 cases were randomly divided into three groups, based on class I, II, III classification, with 30 cases in each group (Fig. 2).

The present study was conducted in patients who were seeking orthodontic treatment in the Orthodontic department of Shorsh teaching dental center in Sulaimani City. Ethical committee approval was obtained before starting the study (Appendix I). 


\section{Criteria For Selecting The Cases}

1- Patients originating from Sulaimani Governorate, as ethnically verified by patient histories (all three grandparents of both parents were Kurdish and from Sulaimaniyah Governorate).

2- Patients aged between 18 and 28 years old.

3- Patients with complete permanent dentition including second molars.

4- No history of orthodontic treatment or orthognathic surgery.

5- No history of craniofacial trauma.

6- No cranial or facial malformation.

7- No TMJ disorder or pain.

When the patient came to the dental center seeking orthodontic treatment, informed consent was not taken for exposure to a lateral cephalogram, because a lateral cephalogram and orthopantogram is required as part of the routine diagnosis procedure.

Two finger method by Foster was used for the initial classification of the sagittal skeletal malocclusion (9). Then the researcher filled in the data recording sheet for each case (appendix II). After that, the patients were referred for a lateral cephalometric radiograph (ceph). All the cephs were taking by one radiologist. These cephs were obtained using the cephalogram [pax-i3D system (Pano-Cephalo-CT), 2014]. The machine was set at 84 kilovoltage peak $(\mathrm{kVp}), 10.0$ milliampere $(\mathrm{mA})$ and exposure time of 1.2 seconds (s). Cephs were taken with teeth in centric occlusion, lips in relaxed posture and the head in the natural head position with the Frankfort plane parallel to the floor (10).

\section{Cephalometric landmarks and planes used in this study for analyses $(3,6)$}

\section{S}

The midpoint of the pituitary fossa (sella turcica).

\section{M}

The midpoint of the premaxilla, identified as the mid-point of the largest circle that could be drawn in the premaxilla tangent to the anterior and superior walls of the premaxilla.

G

Center of the largest circle tangent to the anterior, posterior and internal inferior surfaces of the mandibular symphysis. 


\section{Point A}

The deepest midline point on the premaxilla between the anterior nasal spine and prosthion, near the apex of the central incisor root.

\section{Point B}

The deepest midline point of the bony curvature of the mandible.

\section{Nasion $(\mathrm{N})$}

In the frontonasal suture at the most anterior point.

C

Condylion, the midpoint of the condyle.

\section{Functional occlusal plane}

A line drawn through the region of the overlapping cusps of the first premolars and first molars.

\section{ANB \\ SNA-SNB \\ Wits appraisal}

horizontal distance between two lines, $\mathrm{AO}$ and $\mathrm{BO}$, formed by drawing two lines perpendicularly from point $A$ and point $B$ to the functional occlusal plane.

\section{Beta angle}

The center of the condyle and point $B$ are joined by $C-B$ line. A perpendicular line is then drawn from point $\mathrm{A}$ to the $\mathrm{C}-\mathrm{B}$ line angle. The Beta angle is the angle between this perpendicular line and the $\mathrm{C}-\mathrm{B}$ line.

\section{W angle}

is formed by drawing a perpendicular line from point $M$ to the $S-G$ line.

After measuring the following variables: ANB, Beta angle and Wits appraisal, separately for each patient as shown in (Fig. $3 A, B, C)$, the patients were classified into class I, II or III skeletal pattern groups, two of the three parameters were required to meet the same criteria and be within the same class (6). Table 1 shows the distribution of the patients who fulfilled the criteria across the class I, II, and III study groups. 
Table 1

The criteria that included in the classes I, II, or III skeletal pattern for grouping of study

\begin{tabular}{|llll|}
\hline $\begin{array}{l}\text { Skeletal } \\
\text { class }\end{array}$ & $\begin{array}{l}\text { ANB } \\
\text { angle } \\
(11)\end{array}$ & Wits appraisal (12) & Beta angle (13) \\
\hline Class I & $\begin{array}{l}2^{\circ} \text { to } \\
4^{\circ}\end{array}$ & $\begin{array}{l}\text { Coincidence of } \mathrm{AO} \text { and } \mathrm{BO} \text { in females or } \\
\mathrm{BO} 1 \mathrm{~mm} \text { ahead of } \mathrm{AO} \text { in males }\end{array}$ & $\begin{array}{l}\text { Between } 27^{\circ} \text { to } 35^{\circ} \text { and clinically a } \\
\text { pleasant (almost straight) profile }\end{array}$ \\
\hline Class II & $>4^{\circ}$ & $\begin{array}{l}\text { AO ahead of } \mathrm{BO} \text { in females or } \mathrm{AO} \\
\text { coinciding with or ahead of } \mathrm{BO} \text { in males }\end{array}$ & $<27$ \\
Class III & $<2^{\circ}$ & $\begin{array}{l}\text { BO ahead of } \mathrm{AO} \text { in females or BO ahead } \\
\text { of AO by more than } 1 \mathrm{~mm} \text { in males }\end{array}$ & $>35^{\circ}$ \\
\hline
\end{tabular}

All landmark identification and measurements were done with the use of the software program (Easy Dent 4, software version: 4,14,1 (2012)). This software program had options for adjustment of the radiograph by adjusting the contrast and brightness to facilitate the identification of the landmarks, in addition to zoom option and magnification for better viewing and differentiation of the landmarks. All the tracings were performed by the principal investigator (Mohammed sh).

After sample classification, W angle was constructed and measured (Fig. 4). According to Bhad et al. (6), W angle between $51-56^{\circ}$ is considered as class I skeletal pattern, while an angle less than $51^{\circ}$ is considered as skeletal class II relationship, and an angle greater than $56^{\circ}$ is considered as skeletal class III (6).

To assess the reliability and reproducibility of the Ceph analysis, five parameters/variables from 10 randomly selected cephalograms were traced twice at a two- weeks interval by the same observer and were then tested by the paired t-test, with the mean differences in the measurements found to be nonsignificant. The inter-examiner reliability was assessed in the same way as for the examiners' measurement and then tested using one way analysis of variance (ANOVA). No differences were found in the results.

\section{Statistical analysis}

The Statistical Package for Social Sciences (SPSS, version 22) was used for analyzing data. The Shapiro Wilk test was done to test the normality of the data. According to the P-values, the data were normally distributed. Hence, parametric tests such as ANOVA were used to compare the means of the three study groups. The post-hoc test was used to compare each two groups, Pearson correlation coefficient ( $r$ ) was used to assess the strength of correlation between two numerical variables, and coefficient of variability was used to measure the extent of variability of the variable in relation to the population. The significance alpha level was set at $p$ value of $\leq 0.05$.

\section{Results}


Table 2 shows the descriptive statistics for the mean, standard deviation, coefficient of variability, minimum and maximum for Beta angle, ANB angle, Wits appraisal and W angle.

Table 2

Descriptive statistics for the Beta angle, ANB angle, Wit's appraisal and W angle

\begin{tabular}{|llllllll|}
\hline \multirow{2}{*}{ Beta angle } & & $\mathbf{n}$ & Mean & SD & CV & Min. & Max. \\
& Class I & 30 & 32.387 & 2.96 & 0.09 & 28 & 40 \\
\cline { 2 - 8 } & Class II & 30 & 25.233 & 3.10 & 0.12 & 18.3 & 30 \\
\cline { 2 - 8 } ANB angle & Class III & 30 & 42.957 & 6.39 & 0.15 & 33 & 61 \\
& Class I & 30 & 2.740 & 0.73 & 0.27 & 1.2 & 4 \\
\cline { 2 - 8 } Wit's appraisal I & Class II & 30 & 5.850 & 1.27 & 0.22 & 4 & 8.9 \\
\cline { 2 - 9 } & Class I & 30 & -.010 & 0.75 & -74.90 & -1 & 2.7 \\
\cline { 2 - 8 } W angle & Class II & 30 & 4.320 & 2.37 & 0.55 & 1.5 & 9.8 \\
\cline { 2 - 8 } & Class III & 30 & -6.060 & 3.88 & -0.64 & -15.6 & -1.4 \\
\hline & Class I & 30 & 54.1 & 3.31 & 0.06 & 52.3 & 56.2 \\
\hline
\end{tabular}

Table 3 shows the differences found in the means of Beta angle, ANB, Wits appraisal and W angle readings between and within the three classes, which were all significant $(p<0.001)$. 
Table 3

ANOVA and post-hoc (LSD) test results of Table 2

\begin{tabular}{|c|c|c|c|c|}
\hline & & $p$ (ANOVA) & LSD groups & $\mathrm{p}(\mathrm{LSD})$ \\
\hline \multirow[t]{3}{*}{ Beta angle } & Class I & \multirow[t]{3}{*}{$<0.001$} & Class I X Class II & $<0.001$ \\
\hline & Class II & & Class I X Class III & $<0.001$ \\
\hline & Class III & & Class II X Class III & $<0.001$ \\
\hline \multirow[t]{3}{*}{ ANB angle } & Class I & \multirow[t]{3}{*}{$<0.001$} & Class I X Class II & $<0.001$ \\
\hline & Class II & & Class I X Class III & $<0.001$ \\
\hline & Class III & & Class II X Class III & $<0.001$ \\
\hline \multirow[t]{3}{*}{ Wits appraisal } & Class I & \multirow[t]{3}{*}{$<0.001$} & Class I X Class II & $<0.001$ \\
\hline & Class II & & Class I X Class III & $<0.001$ \\
\hline & Class III & & Class II X Class III & $<0.001$ \\
\hline \multirow[t]{3}{*}{ W angle } & Class I & $<0.001$ & Class I X Class II & $<0.001$ \\
\hline & Class II & & Class I X Class III & $<0.001$ \\
\hline & Class III & & Class II X Class III & $<0.001$ \\
\hline
\end{tabular}

\section{Correlation Between The Study Parameters}

Table 3 shows that in class I patients, all of the correlations between the studied parameters were weak and not significant $(r<0.4$, and $P>0.05)$, except for the correlation between $W$ angle and Wits appraisal, which was a significant positive correlation $(r=0.382, p=0.037)$. In class II patients, all the correlations were weak and not significant, except for a negative, moderate strength significant correlation between $\mathrm{W}$ angle and ANB angle $(r=-0.563, p=0.001)$.

The picture is different regarding class III patients. Strong inverse significant correlation was detected between Beta angle and ANB angle $(r=-0.725, p<0.001)$. The same was found for the correlation between Beta angle and Wits appraisal $(r=-0.820, p<0.001)$. A nearly strong positive significant correlation was detected between the Beta angle readings and $W$ angle readings $(r=0.686, p<0.001)$. Strong significant positive correlation was detected between ANB angle and Wits appraisal $(r=0.719, p<$ 0.001). There was a negative strong significant correlation between ANB angle readings and $W$ angle readings $(r=-0.723, p<0.001)$. Finally, an inverse, nearly strong, significant correlation was observed between Wits appraisal and $W$ angle $(r=-0.678, p<0.001)$.

\section{Discussion}


Evaluation of the antero-posterior jaw relationship is an obligatory step in orthodontic diagnosis and treatment planning and this procedure is essentially done by cephalometric analysis (8).

Both angular and linear variables are utilized cephalometrically to analyze the skeletal sagittal jaw relationship. A search of the literature indicated that various parameters are available to assess the sagittal relationship but none of them can be applied with maximum reliability (14).

Therefore, this study aimed to analyze different geometrical and statistical variations in cephalometric parameters which were used to indicate the antero-posterior jaw relationship in class I, class II and class III malocclusions and to compare the accuracy of the recently proposed $\mathrm{W}$ angle with these parameters for measuring antero-posterior jaw discrepancies in a sample of the Kurdish population in Sulaimani City.

All sagittal jaw analysis parameters invented over the years are affected by at least one of the following factors: jaw rotations, poor reproducibility of landmarks, patient's age changes during orthodontic treatment and growth changes in reference planes (15). Therefore, to overcome the limitations of the other parameters the $\mathrm{W}$ angle was produced.

The ANB angle was developed by Riedel in 1952(11). Until now it is considered the most popular and widely used angle for assessing the sagittal jaw relationship. However, it is affected by jaw rotation due to orthodontic treatment or growth. In addition, any displacement in point $\mathrm{N}$ has an influence on ANB values (11). When using the ANB angle many factors, including the length of the anterior cranial base, growth rotation of the jaws, vertical growth and patient age, should be considered, which makes the assessing of this angle much more complicated (16). In the present study, the mean values of this angle were near to those of Riedel's standards and the results of our study showed that the ANB angle values are significant among the groups. However, it is affected by various factors which can often lead to error.

To overcome the controversies surrounding the ANB angle, the Wits appraisal was introduced by Jacobson in 1975 (17). Although landmarks identification or jaw rotations have no effect on it, its accuracy is affected by the need to correctly identify the functional occlusal plane, which can sometimes be impossible, especially in patients with open bite, in mixed dentition, multiple impactions, missing teeth, severe cant of the occlusal plane, and skeletal asymmetries, or steep curve of Spee (18). Additionally, the functional occlusal plane may be changed by orthodontic treatment, which can influence the Wits measurement. Therefore, in these cases the Wits appraisal will not reflect pure sagittal changes of the jaws (3). The mean values of the present study were near to those of Jacobson, the results showing significant differences in all three groups. However, the location of the functional occlusal plane itself was difficult, as confirmed by Moore et al. and Ishikawa et al.(19,15).

The present study showed that the Beta angle values were statistically significant among all groups, as supported by Biak and Ververidou, who stated that the Beta angle remains relatively stable even when the jaws are rotated, and it does not depend on the functional occlusal plane or cranial landmarks (13). When there is clockwise or counterclockwise rotation of the jaws, the Beta angle can assess the sagittal jaw relationship more accurately. Nonetheless, it still uses point A and point $B$ which are considered to be 
affected by alveolar bone remodeling associated with growth or orthodontic movement of the incisor teeth (20).

To overcome some of the above limitations of other parameters, a measurement was developed that was named the $\mathrm{W}$ angle. This angle does not depend on any unstable landmarks or dental occlusion and therefore would be especially valuable to assess true sagittal changes due to growth and orthodontic treatment. In the present study the mean values of $W$ angle were near to those found in the Bhad et al. (6) and Al Mashhadany (21) studies. The present study disagrees with Mittal et al. study (5), although this might be due to difference in sample size or ethnic differences. The present study shows that $\mathrm{W}$ angle values were statistically highly significant among the groups. This agrees with Bhad et al. study which proposed that this angle is an indicator for sagittal skeletal dysplasia (6). As W angle uses three stable landmarks: point $S$, point $M$, and point $G$, the $W$ angle remains relatively stable even when the jaws are rotated or growing vertically. This is because of rotation of the S-G line along with jaw rotation, which carries the perpendicular from point $\mathrm{M}$ with it (6).

Another advantage of $\mathrm{W}$ angle is that it can be a valuable tool for planning orthopedic or orthognathic procedures as this angle is independent of cranial base length which will be affected by the position of point $\mathrm{N}$ and can sometimes camouflage true skeletal class I, II, and III patterns (3). The present study results showed that the coefficient of variability was highest for Wits appraisal and lowest for $\mathrm{W}$ angle in all three classes, agreeing with Mittal et al. (4) and Sharmaet al., (7) studies. This indicates that Wits appraisal is a highly variable parameter and $W$ angle is the least variable and most homogeneously distributed parameter in intra-group comparisons.

\section{Correlation of the study parameters in class I patients}

The present study showed that in class I group, all of the correlations between the studied parameters were weak and not significant, except for the correlation between $\mathrm{W}$ angle and Wits appraisal, where there was significant positive correlation. The findings agree with Mittal et al. (5) study, but disagree with Sharmaet al., (7) study which found that in class I subjects ANB angle correlated positively with Wits appraisal. Additionally, our study disagrees with Pervez and Ahmed (8) and Al-Mashhadany (21) studies which reported strong negative correlation between W angle and ANB angle in CL I malocclusion.

\section{Correlation of the study parameters in class II patients}

The present study showed that in class II group, there was a negative, moderate strength significant correlation between W angle and ANB angle, which agrees with Sharma et al. (7) and Pervez and Ahmed (8) studies but disagrees with the study by Mittal et al. (5) which found a moderate negative correlation between $\mathrm{W}$ angle and Wits appraisal.

\section{Correlation of the study parameters in class III patients}

The findings of this study showed a strong negative significant correlation between ANB angle and Beta angle, and a strong significant positive correlation between ANB angle and Wits appraisal. These results 
agree with Mittal et al. (5) study. In CL III group, the W angle showed strong positive significant correlation with the Beta angle, and significant correlation with Wits appraisal. Moreover, there was a negative strong significant correlation between the ANB angle readings and the $W$ angle readings. These results agree with the findings by Pervez and Ahmed (8), and AL Mashhadany (21). However, they disagree with the Mittal et al. (5) results which showed only a negative correlation between $\mathrm{W}$ angle and ANB angle and no significant correlation between other parameters.

The Beta angle is similar to $\mathrm{W}$ angle in being unable to determine which jaw is prognathic or retrognathic in class II and class III skeletal cases. To clarify this, clinicians should be aware of the importance of other cephalometric measurements (8). The relatively new $\mathrm{W}$ angle is evidently the most stable and reliable angle for measuring skeletal sagittal discrepancies (22).

\section{Conclusions}

Among the study sample of Kurdish young adults in Sulaimani City, the mean respective values of ANB angle for class I, II, and III malocclusion were $2.74^{\circ}, 5.85^{\circ}$ and $-3.29^{\circ}$, for B angle they were $32.39^{\circ}$, $25.23^{\circ}$ and $42.96^{\circ}$, while for $\mathrm{W}$ angle they were $54.1^{\circ}, 48.34^{\circ}$ and $60.07^{\circ}$. The ANB angle, Beta angle, Wits apprasial and $\mathrm{W}$-angle are significant parameters for assessing the sagittal jaw relationship between maxilla and mandible; however, to overcome the limitations of each at least 2-3 parameters should be used.

\section{Declarations}

\section{Acknowledgments:}

We would like to acknowledge and thank the staff of our institution for their assistance and support to accomplish this study.

\section{Funding}

The study was not supported.

\section{Contributions}

Mohammed sh conducted the research, recruited the sample, performed the statistical analysis. Ali TM designed the research project and supervised the research. Rashid ZJ drafted and finalized the manuscript. The author(s) read and approved the final manuscript.

\section{Ethics approval and consent to participate}

All investigations and procedures were conducted according to the principles expressed in the Declaration of Helsinki. Ethical approval for the retrospective study was not required. 


\section{Consent for publication}

All authors give their consent for the publication of the research article.

\section{Competing interests}

The authors declare that they have no competing interests.

\section{Data Availability}

The datasets used and/or analysed during the current study are available from the corresponding author on reasonable request.

\section{References}

1. Singh A, Jain A, Hamsa PR, Ansari A, Misra V, Savana K, Yadav A. Assessment of sagittal discrepancies of jaws: A review. Int J Adv Health Sci. 2015;1(9):29-4.

2. Jain SO, Raghunath N, Muralidhar NA. A comparison of W angle, Pi Angle and YEN angle as an indicator for assessing anteroposterior Skeletal dysplasia in various malocclusion among regional population: a cephalometric study. IJDRD. 2018;8(3):29-40.

3. Gor J, Kubavat A, Desai M, Mahida K, Modh A, Vaghela A. W Angle: Sagittal Jaw Dysplasia Indicator for orthodontic diagnosis outcome. JMSCR. 2019;8(5):61-5.

4. Mittal D, Venkatesh S, Shivamurthy P, Mathew S. A" new vista" in the assessment of antero-posterior jaw relationship. APOS Trends in Orthodontics. 2015;5(4):151-55.

5. Mittal A, Bohra S, Murali PS, Saidath K and Krishnanayak US. An evaluation of YEN and W angle in the assessment of anteroposterior jaw relationship. J Indian Orthod Soc. 2016;50(1): 26-0.

6. Bhad WA, Nayak S, Doshi UH. A new approach of assessing sagittal dysplasia: the W angle. Eur J 2013;35(1):66-0.

7. Sharma R, Sharma K, Mathur A, Preethi N, Agarwal V, Singh S and Satija N. Comparison of W angle with different angular and linear measurements in assessment of sagittal skeletal relationship in Class I and Class II patients in Jaipur population-A cephalometric study. OHDM. 2015;14(3):155-60.

8. Pervez $\mathrm{H}$ and Ahmed I. A new cephalometric tool $\mathrm{W}$ angle in the evaluation of anteroposterior skeletal discrepancy in orthodontic patient. JDH S. 2014;1(3):299-04.

9. Foster TD. A textbook of orthodontics 2nd ed. St Louis: Blackwell Scientific Publications, Mosby Book Distributors. 1982. Page 25-41.

10. Major PW, Johnson DE, Hesse KL, Glover KE. Effect of head orientation on posterior anterior cephalometric landmark identification. Angle Orthod. 1996;66(1):51-0.

11. Riedel RA. The relation of maxillary structures to cranium in malocclusion in normal occlusion. Angle Orthod. 1952;22(3):140-45.

12. Jacobson A. Update on the Wits appraisal. Angle Orthod. 1988;58(3):205-19. 
13. Baik CY, Ververidou M. A new approach of assessing sagittal discrepancies: the Beta angle. Am J Orthod Dentofacial Orthop. 2004;126(1):100-05.

14. Doshi J, Trivedi K, Shyagali T. Predictability of YEN angle \& appraisal of various cephalometric parameters in the assessment of sagittal relationship between maxilla and mandible in angle's class II malocclusion. Peoples J Sci Res. 2012;5(1):1-8.

15. Ishikawa $H$, Nakamura S, Iwasaki H, Kitazawa S. Seven parameters describing anteroposterior jaw relationships: postpubertal prediction accuracy and interchangeability. Am J Orthod Dentofacial Orthop. 2000;117(6):714-20.

16. Jacobson A. Application of the" Wits" appraisal. Am J Orthod.1976;70(2):179-89.

17. Jacobson A. The Wits appraisal of jaw disharmony. Am J Orthod1975; 67 (2):125-38.

18. Sherman SL, Woods M and Nanda RS.The longitudinal effects of growth on the Wits appraisal. Am J Orthod. 1988;93(5): 429-36.

19. Moore RN, DuBois LM, Boice PA, Igel KA. The accuracy of measuring condylion location. Am J Orthod Dentofacial Orthop. 1989; 95(4):344-7.

20. Rushton R, Cohen A M, Linney A D. The relationship and reproducibility of angle ANB and the Wits appraisal. Br J Orthod. 1991;18(3):225-31.

21. Al-Mashhadany $S M$. The relation between $W$ angle and other methods used to assess the sagittal jaw relationship. J Bagh Coll Dentistry. 2012;24(2):144-9.

22. Gupta AK, Kumar A, Ashraf K, Hussain K, Kumar A, Kulshrestha R. Establishment of cephalometric norms of Yen, $W$ and Beta angle with assessment of sagittal jaw relationship in Eastern Indian population. Indian J Orthod Dentofacial Res. 2019;5(2):63-6.

\section{Figures}




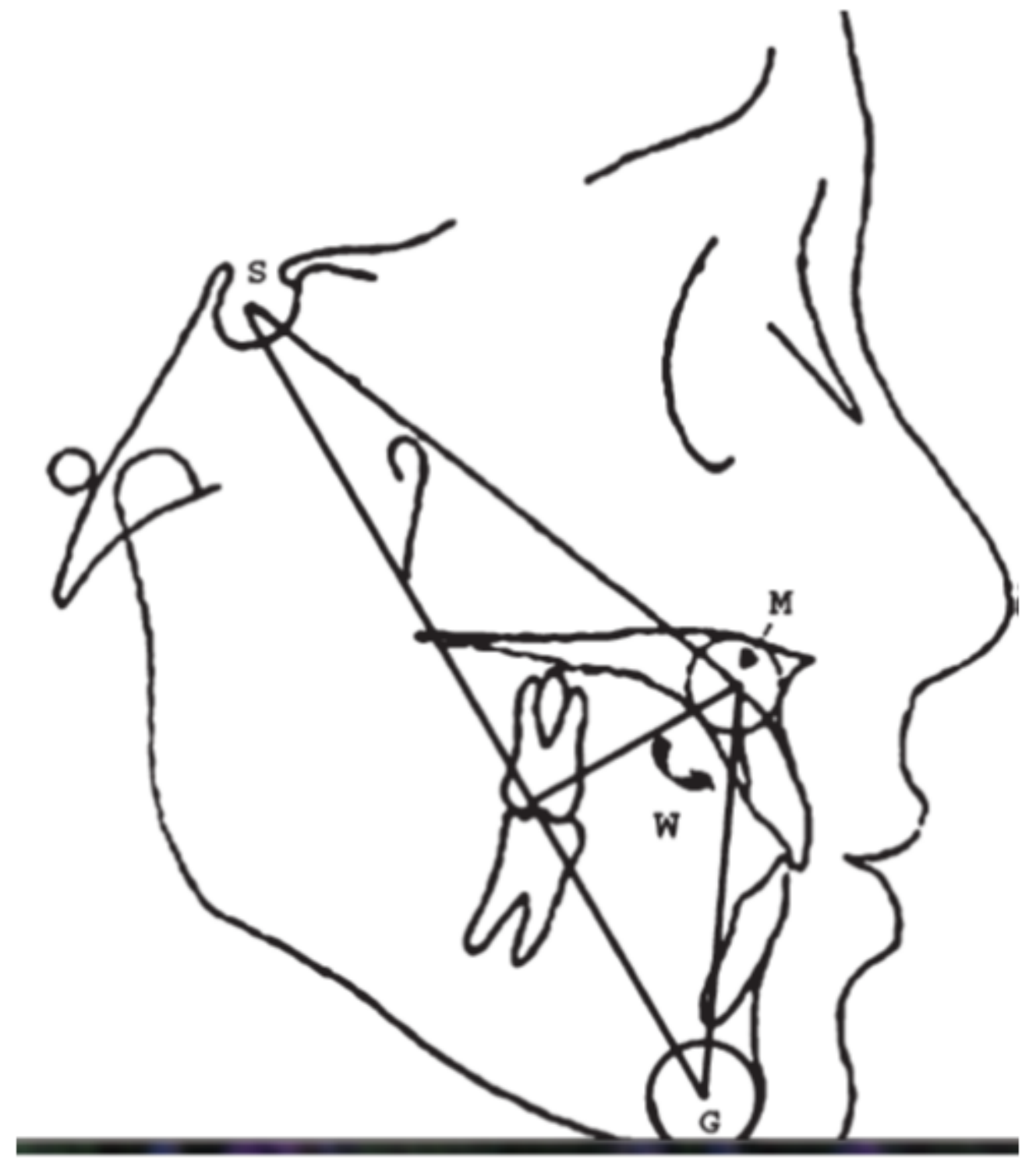

Figure 1

The construction and mode of measuring the W angle (3)

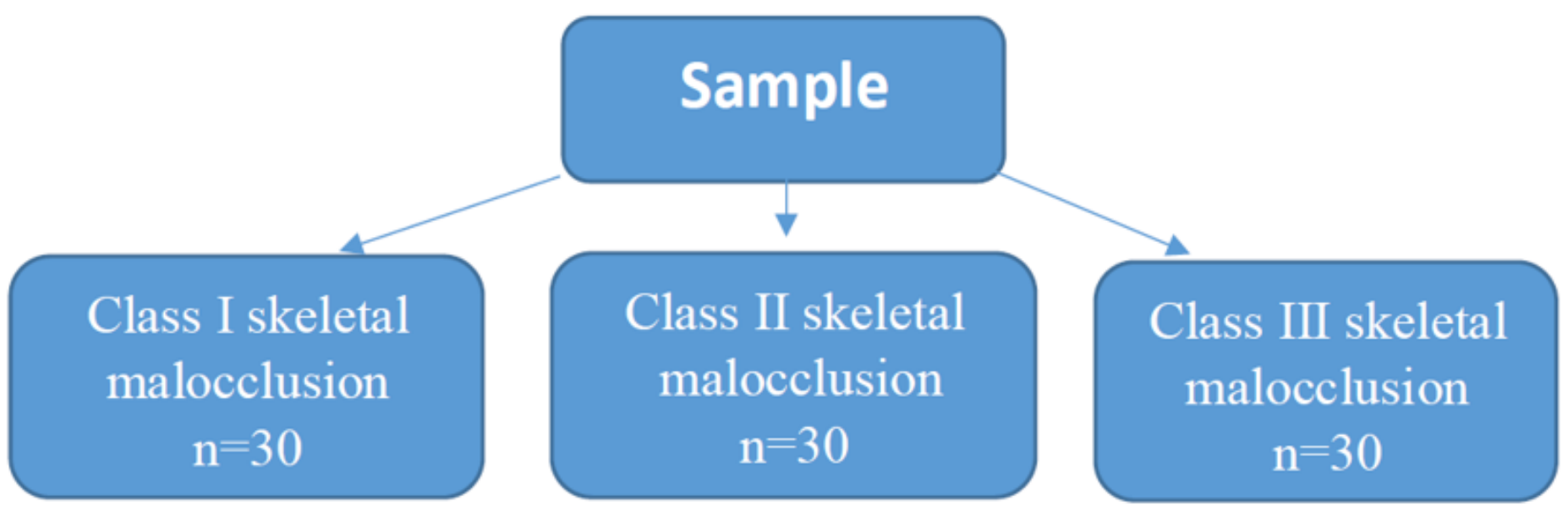


Figure 2

Distribution of the sample

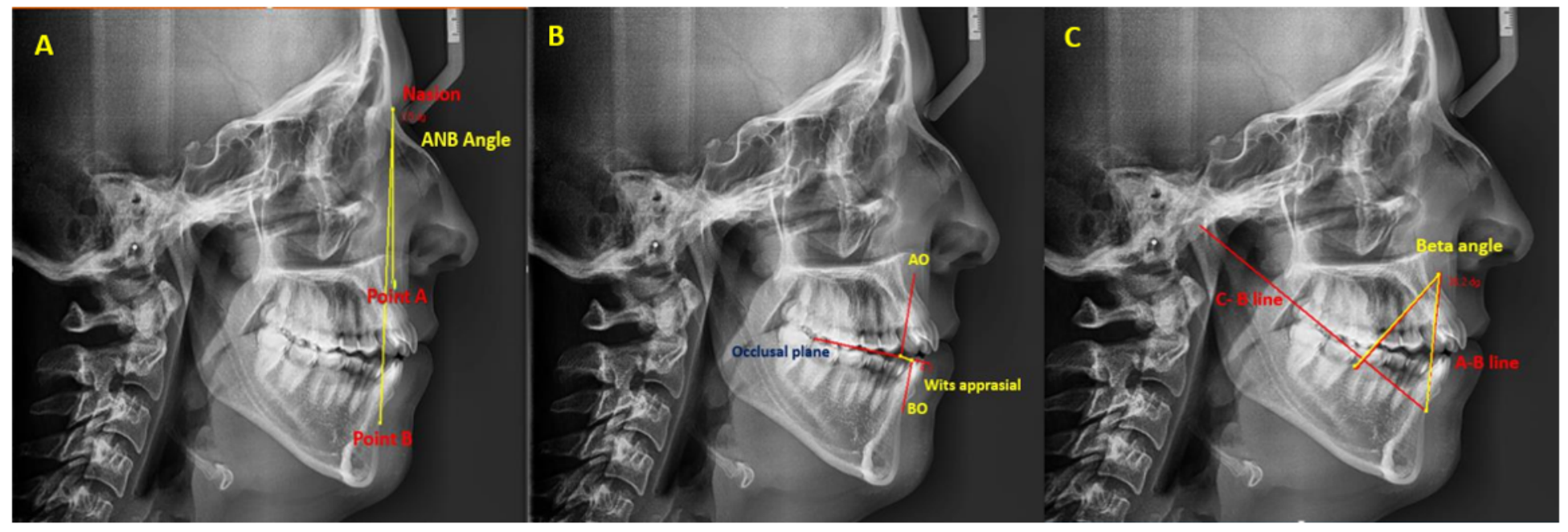

Figure 3

A) ANB angle, B) Wits appraisal, and C) Beta angle identification 


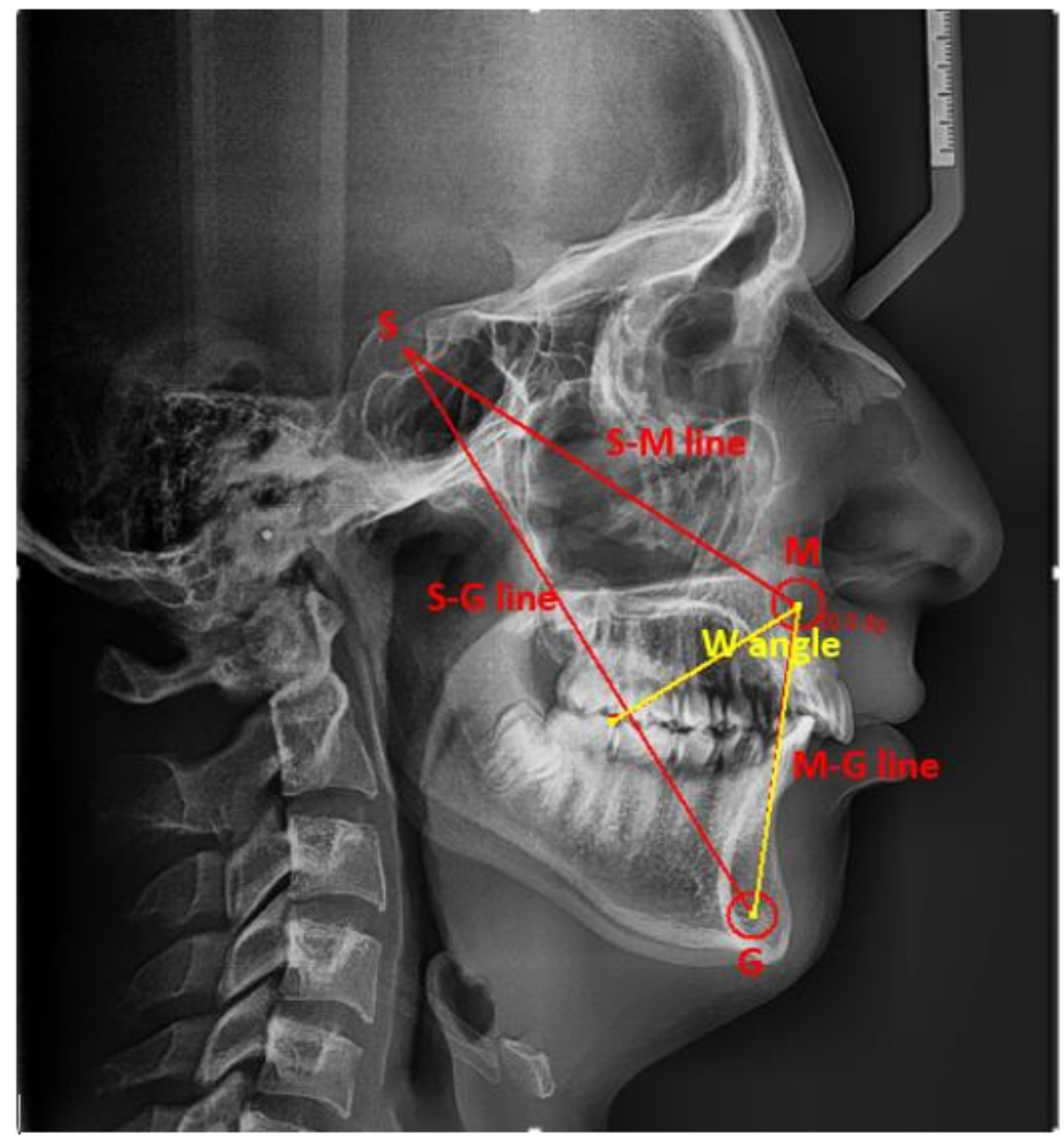

Figure 4

Wangle identification

\section{Supplementary Files}

This is a list of supplementary files associated with this preprint. Click to download.

- AppendicesAdditionalinformation.pdf 